\title{
The antifungal Aureobasidin A and an analogue are active against the protozoan parasite Toxoplasma gondii but do not inhibit sphingolipid biosynthesis - Corrigendum
}

\author{
A. Q. I. AlQAisi, A. J. MBEKEANi, M. BASSAS LLORENS, A. P. ELHAMMER and \\ P. W. DENNY \\ doi: 10.1017/S0031182017000506, Published by Cambridge University Press, 10 May 2017.
}

The authors apologise for errors which appear in the legend of Figure 2. Please find below the corrected legend.

Fig. 2. ED50 of Aureobasidin A (AbA, A-D) or Compound 20 (Cpmd 20, E-H) - $\mu$ g mL-1; (95\% Confidence Interval) - against the Toxoplasma RH tachyzoite form in HFF cells. 6 days post addition of the compounds. In agreement with Sonda et al. (2005), both compounds were non-toxic to HHF cells under the conditions employed. A and E: no wash out post-compound addition; B and F: wash out $2 \mathrm{~h}$ post-compound addition; $\mathrm{C}$ and $\mathrm{G}$ : wash out $8 \mathrm{~h}$ post-compound addition; $\mathrm{D}$ and $\mathrm{H}: 2 \mathrm{~h}$ pre-treatment of isolated parasites preinfection. Calculated using GraphPad Prism 7, log (inhibitor) vs normalized response - Variable slope. $>10 \mu \mathrm{g} \mathrm{mL}-1$ - ED50 could not be determined. Representative in triplicate dataset.

\section{REFERENCE}

Alqaisi, A. Q. I., Mbekeani, A. J., Bassas Llorens, M., Elhammer, A. P. and Denny, P. W. (2017). The antifungal Aureobasidin A and an analogue are active against the protozoan parasite Toxoplasma gondii but do not inhibit sphingolipid biosynthesis. Parasitology. Published by Cambridge University Press, 10 May 2017. doi: 10.1017/S0031182017000506

Parasitology (2018), 145, 156. (C) Cambridge University Press 2017. This is an Open Access article, distributed under the terms of the Creative Commons Attribution licence (http://creativecommons.org/licenses/by/4.0/), which permits unrestricted re-use, distribution, and reproduction in any medium, provided the original work is properly cited. 